\title{
UM TEXTO, MÚLTIPLAS INTERPRETAÇÕES: ANTROPOLOGIA HERMENÊUTICA E CULTURA ORGANIZACIONAL
}

\section{RESUMO}

Neste artigo pretende-se contribuir para a compreensão do papel exercido pela dimensão simbólica na construção da realidade organizacional. Parte-se da apresentação de dados etnográficos que descrevem um caso ilustrativo de conflitos culturais no universo empresarial. Em seguida, são realizadas algumas reflexões teóricas a partir do caso apresentado. Nesse momento, procura-se: a) empreender uma breve revisão de literatura sobre a antropologia simbólico-interpretativa tomando como referência os trabalhos de Clifford Geertz, principal representante dessa corrente da disciplina antropológica, bem como as idéias de alguns de seus interlocutores; e b) traduzir as idéias originárias da antropologia interpretativa ou hermenêutica para pensar a dinâmica cultural nas organizações. O propósito final do artigo é, portanto, fazer avançar o debate sobre cultura organizacional, apresentando as contribuições dessa perspectiva antropológica como uma possibilidade de superação dos limites deixados pela corrente funcionalista até então dominante nesse subcampo de estudos.

\section{Pedro Jaime Júnior}

Coordenador Acadêmico das Faculdades Jorge Amado, pesquisador do CETEAD, mestre em Antropologia Social pela UNICAMP e graduado em Administração pela UFBA.

E-mail: pedrojaime@uol.com.br

\begin{abstract}
This article intends to contribute for the understanding concerning the symbolic dimension on the construction of the organizational reality. At first it presents ethnographic data which describe an illustrative case of cultural conflicts in the business universe. Afterwards, some theoretical reflections are accomplished starting from the presented case. At this moment, it intends to seek: a) an abbreviation of literature revision on the symbolic-interpretative anthropology taking as reference Clifford Geertz's works, main representative of this current of anthropological discipline, as well as some authors who have studied and criticized his work; $b$ ) the translation of original ideas of the interpretative or hermeneutics anthropology to reflect about the cultural dynamics in the organizations. The final purpose of the article is therefore make the advance of the debate about organizational culture, presenting the contributions of that anthropological perspective as a possibility of overcoming the limits left by the functionalist current which has been dominant in this sub-field of studies until nowadays.
\end{abstract}

PALAVRAS-CHAVE Antropologia interpretativa, metáforas, cultura, cultura organizacional, teoria das organizações. KEY WORDS Interpretative anthropology, metaphors, culture, organizational culture, theory of organizations. 


\section{PEDRO JAIME JÚNIOR}

\section{INTRODUÇÃo}

A discussão acerca das dimensões simbólicas no universo organizacional possui remotas raízes históricas. Seu itinerário teórico deve ser traçado a partir do Experimento de Hawthorne, empreendido por Elton Mayo e seus colaboradores, entre os anos 1920 e 1930 do século passado. Nesse estudo já estava presente um "protoconceito" de cultura organizacional, entendida como sistemas ideológicos simbólicos (Aktouf, 1990).

Todavia, é a partir do final da década 1970 que a corrente da cultura organizacional tem desenvolvimento sem precedentes no campo da teoria das organizações, passando a constituir uma área disciplinar específica, com seus especialistas, suas escolas, suas tendências e seus "clássicos". Alguns estudiosos já realizaram balanços sobre o desenvolvimento desse subcampo dos estudos organizacionais (Smircich, 1983; Aktouf, 1990; Schwartzman, 1993; Wright, 1994; Pépin, 1998). Aktouf (1990) e Pépin (1998) apontam a existência de pelo menos duas abordagens distintas nesse domínio.

A primeira, de clara inspiração funcionalista e detentora de uma perspectiva gerencialista, é por eles denominada de mainstream. Diversos autores são classificados nessa vertente - ainda que suas produções teóricas sejam matizadas -, dentre os quais podemos destacar: Schein, Pettigrew, Ouchi, Charles Handy e as duplas Peters e Waterman, Deal e Kennedy, e Pascale e Athos. Eles parecem concordar em relação a alguns pressupostos básicos, a saber: a) toda organização possui uma cultura; b) essa cultura explica muitos dos fenômenos que ocorrem na organização; c) ela favorece ou dificulta a performance organizacional; d) a cultura pode ser diagnosticada e, aplicando-se certas metodologias, gerenciada, transformada, ou até inteiramente criada; e) a liderança é o processo que determina a formação e a mudança da cultura; e f) um dos papéis mais importantes dos líderes nas organizações é justamente a criação, a gestão e, se necessário, a mudança da cultura.

A essa abordagem, Aktouf (1990) e Pépin (1998) contrapõem uma perspectiva crítica ou sócioantropológica. Os membros dessa segunda vertente não aceitam o pressuposto de que a cultura organizacional possa ser gerenciada. Para eles, tal pressuposto é vítima de um reducionismo utilitarista, configurando uma operação ideológica que tenta aprisionar o simbólico nos ditames da racionalidade instrumental. Estudos como os de Chanlat (1990), de Dupuis (1990) e do próprio Aktouf (1990), dentre outros, embora também possuam divergências, podem ser aqui agrupados.
Partindo dessa segunda vertente, pretende-se, neste artigo, contribuir para a compreensão do papel exercido pela dimensão simbólica na construção da realidade organizacional. Inicialmente é apresentado um caso ilustrativo de conflitos culturais no universo empresarial. Em seguida, são realizadas algumas reflexões teóricas a partir do caso. Nesse momento, procura-se: a) empreender breve revisão de literatura sobre a antropologia simbólico-interpretativa, tomando como referência os trabalhos de Clifford Geertz, principal representante dessa corrente da disciplina antropológica, bem como as idéias de alguns de seus interlocutores; e b) traduzir as idéias originárias da antropologia interpretativa para pensar a dinâmica cultural nas organizações. O propósito final do artigo é, portanto, fazer avançar o debate sobre cultura organizacional, apresentando as contribuições dessa perspectiva como uma possibilidade de superação dos limites deixados pela corrente funcionalista, até então dominante nesse subcampo de estudos.

\section{CLIVAGENS INTERPRETATIVAS E CONFLITOS CULTURAIS EM UMA JOINT-VENTURE}

Os dados etnográficos descritos a seguir referem-se a uma pesquisa de campo de aproximadamente quatro anos, empreendida pelo antropólogo Guilhermo Ruben, da Unicamp, em uma empresa binacional argentino-brasileira (Ruben, 1999). Vale ressaltar que ele mantém em sigilo o nome da empresa, denominando-a a firma.

Em 1987, dois grupos de executivos do setor metalúrgico, um brasileiro e um argentino, resolveram promover o estabelecimento de uma joint-venture. Ao fim das negociações, o grupo argentino ficou responsável por $51 \%$ da composição acionária, ao passo que o brasileiro deteve os $49 \%$ restantes. As diferenças culturais presentes nesse encontro etnográfico potencializavamse, uma vez que os grupos eram internamente heterogêneos. Do lado argentino estavam um italiano, que residia há muitos anos na Argentina, e um descendente de judeus. O primeiro, técnico metalúrgico de origem operária; o segundo, um engenheiro, membro das camadas médias urbanas. Eles dividiam em partes iguais a parcela argentina do capital da empresa. Do lado brasileiro, por seu turno, havia quatro profissionais extremamente diferentes entre si. O primeiro era um nisei casado com uma brasileira, com nível secundário completo e já proprietário de uma planta industrial de médio porte em São Paulo. Ele, que posteriormente saiu da sociedade, 
possuía 40 dos $49 \%$ do pacote acionário brasileiro, ao passo que os demais dividiam os 9\% restantes. Estes últimos podem ser assim caracterizados: um profissional saído de um setor tradicional dos serviços públicos, fortemente inscrito em uma tradição religiosa fundada no espiritismo, com longa experiência no mercado, tendo atuado nas áreas de produção e marketing, e com extraordinário conhecimento formal e informal desse segmento; um jovem formado em Engenharia de Alimentos, pela Unicamp, com pouca experiência de trabalho, originário de tradicional família mineira e com perfil de yuppie, ou seja, empreendedor, sonhador, ambicioso; e, finalmente, um trabalhador proveniente de famílias de operários de São Paulo, que havia ingressado muito jovem no mercado de trabalho metalúrgico, o que lhe imprimiu traços de cultura operária tradicional, mas que teve acesso ao ensino universitário, em faculdades privadas da Grande São Paulo sem tradição de ensino e pesquisa.

A empresa tinha participação informal no Mercosul, visto que, no momento em que foi criada, o bloco econômico estava ainda em etapa de discussão entre as diversas representações - governamentais, empresariais e sindicais - dos países envolvidos.

O negócio da firma era fabricação, importação e comercialização de equipamentos para cozinhas industriais. Seu mercado-alvo era composto por cadeias de restaurantes orientados para fast-food: hospitais, universidades e, de maneira geral, todo estabelecimento público ou privado voltado para a oferta de grande quantidade de refeição em curto período de tempo. No Brasil, e mais precisamente em São Paulo, existem diversas empresas consagradas a esse tipo de atividade. Ou seja, a firma tinha um mercado potencial promissor.

Praticamente todas as condições técnicas favoráveis à alavancagem dos negócios faziam-se presentes, dentre as quais se podem destacar:

a) Experiência anterior dos parceiros - o que garantia um conhecimento extraordinário do setor. Os sócios argentinos haviam sido proprietários da maior indústria desse ramo de atividade em seu país, que era também a líder na América Latina. Além disso, um dos brasileiros da firma ocupara, durante dez anos, o cargo de diretor da maior empresa concorrente.

b) Saúde financeira - propiciada pelo aporte de capital feito pelos sócios argentinos, que possuíam uma estratégia de penetração no mercado brasileiro - garantindo uma certa independência em relação aos créditos de investimento governamentais ou privados. c) Produtos considerados de alta qualidade. No início de suas atividades no Brasil, a firma importava os produtos quase inteiramente da Argentina.

d) Competitividade da política de preços praticada, levando-se em conta a qualidade e a origem estrangeira dos produtos.

e) Participação de mercado - assegurada por uma carteira de clientes significativa, incluindo McDonald's, Varig, grandes cadeias de hotel, restaurantes e aeroportos brasileiros.

Tudo estava pronto para a decolagem, e os parceiros sentiam-se otimistas com relação ao futuro. Os argentinos e o nisei, em função da condição de acionistas majoritários, ocupariam a presidência. Os demais membros do grupo brasileiro seriam os principais executivos. Eles tinham produtos de boa qualidade, em um mercado enorme e quase virgem. O sucesso parecia inevitável. Entretanto, as expectativas foram rapidamente frustradas e a firma conheceu, ao invés da glória e do sucesso, momentos de desespero e de conflitos lancinantes. As razões? Os membros construíam leituras diferentes da realidade organizacional. Os sócios não conseguiam compatibilizar perspectivas que lhes pareciam radicalmente diferentes.

As clivagens interpretativas surgiram no cotidiano da empresa, especialmente no momento do contato face a face entre brasileiros e argentinos. Inicialmente, esses encontros ocorriam durante uma semana a cada mês. Mas, com o passar do tempo, os argentinos, que nunca tomaram o Brasil como residência, elevaram a frequência de viagens ao país, aumentando o espaço de interação e, em conseqüência, os conflitos.

Em um primeiro nível de análise, Ruben sugere que as perspectivas diferentes são originadas nos preconceitos constatados, de forma não sistemática, como senso comum, ou seja, nos sistemas de representação que os cidadãos de cada país constroem sobre o outro. Essas representações estereotipadas estariam relacionadas ao hábito que muitos argentinos têm de chamar os brasileiros de macaquitos, assim como os bolivianos de bolitas e os paraguaios de paraguas. De acordo com esse estereótipo, os argentinos, possuindo ainda hoje nível de escolaridade superior à média da região, seriam, malgrado as últimas crises econômicas, os "europeus" da América Latina. Por sua vez, os brasileiros, também constroem representações estereotipadas sobre os argentinos. Tais representações reportam-se a um povo muito mentiroso e arrogante (Ruben, 1999). 
Os parceiros, porém, conheciam a rivalidade clássica entre Brasil e Argentina. Eles sabiam, de maneira mais ou menos consciente, que deveriam ultrapassar essa tradicional desconfiança, vencendo seus próprios preconceitos e superando os estereótipos. Portanto, o maior problema da firma não estava aí, como salienta Ruben. Residia nas diferentes interpretações sobre os conceitos elementares da vida cotidiana de toda empresa: valor, trabalho, tempo, espaço, sindicato, trabalhador, governo, sociedade, e tantos outros, que representaram fontes de pequenos e, por vezes, grandes desacordos. Tanto os argentinos quanto os brasileiros achavam que essas clivagens interpretativas eram radicais e irredutíveis. Dentre os diversos conflitos da dinâmica cultural na organização, Ruben destaca certas interpretações conflitantes de tempo e espaço.

\section{Interpretações do tempo: tempo de trabalho versus tempo de lazer}

Não havia consenso sobre o tempo entre os dois grupos de empreendedores. Para os brasileiros, o cotidiano estava relacionado ao trabalho. Já para os argentinos, que vinham ao Brasil de passagem, o trabalho possuía sempre perspectiva de lazer, de um tempo diferente. Não que se divertissem, ou quisessem "fazer a festa". Ao contrário: durante sua estada no Brasil, eles "sofriam" até mais que os colegas brasileiros, uma vez que deixavam casa, família e vida cotidiana para se adaptarem em outro país, outra língua, outra cultura.

O problema não estava situado na "realidade", do que "realmente" se passava, mas na leitura que os atores construíam, em um clima de contradição jamais explicitado, de que os argentinos, apesar de seus esforços físicos e financeiros, estavam se divertindo, e os brasileiros trabalhando duro. Essa não era a verdade, para qualquer que fosse o observador. Todos trabalhavam duro, ao longo de uma jornada de dez a 12 horas. Entretanto, tratava-se de uma imagem que eles faziam de si mesmos. Ocasionalmente, após um dia de trabalho, o grupo saía para jantar em um restaurante. Surgiam então as relações jocosas, do tipo: "Vocês, argentinos, vêm aqui para se divertir! Nós, brasileiros, trabathamos, hoje, como todos os dias". Alegava-se que os argentinos falavam de divertimento, e os brasileiros de trabalho.

A imagem de viagem construída, tanto por uns quanto por outros, estava fortemente associada à tradicional representação de férias, lazer. Ninguém no grupo a percebia enquanto atividade profissional. Aí repousava uma fonte infinita de problemas, invejas e comentá- rios críticos. O resultado? A desconfiança interna aumentava e as decisões estavam sempre contaminadas por esse clima tenso, que tinha origem nas interpretações sobre o tempo, marcadas pela separação entre tempo de viagem, "gandaia", e tempo de trabalho, "batalha" - expressões utilizadas pelos próprios sujeitos sociais. Os parceiros, executivos inteligentes e brilhantes, não chegavam a construir juntos uma comunidade de interpretação sobre essa particular e banal idéia de tempo.

\section{Interpretações do espaço: espaço de operários versus espaço de executivos}

A interpretação do espaço constituía outro grave conflito da firma. O problema entre os dois grupos é que eles ignoravam reciprocamente o valor atribuído à representação do espaço. Isso provocava o aumento da desconfiança e impedia o desenvolvimento "normal" das atividades industriais.

Qual era o problema? Os grupos provinham de experiências diferentes. Conforme afirmado anteriormente, os brasileiros, em sua maioria, eram antigos empregados. Os argentinos, em contraste, eram industriais de sucesso em seu país. Uma oposição marcava a leitura do espaço construída por uns e por outros, em razão de suas distintas trajetórias.

Para os brasileiros, era inconcebível a idéia de trabalhar no mesmo espaço que operários e supervisores. Possuíam uma preocupação secreta de ficar longe dos trabalhadores. Desejando remarcar a condição de proprietários do negócio, os brasileiros queriam, a qualquer preço, ter um espaço privado e distante da fábrica. Partia desse grupo a idéia de conservar o escritório administrativo da firma nas adjacências da Avenida Paulista, onde havia sido instalado inicialmente - separado, portanto, da planta industrial, localizada em Alphaville, município de Barueri, na Grande São Paulo.

A visão dos argentinos era radicalmente diferente. $\mathrm{Na}$ empresa argentina não havia espaços divididos, estando a fábrica e o escritório no mesmo imóvel. Além disso, dado que eram os principais investidores, queriam economizar o máximo.

Ambos os discursos sobre o espaço, com as propostas de ação correspondente, sustentavam-se em argumentos muito bem elaborados. Do lado brasileiro, destacava-se que a existência de um escritório central, em um espaço separado da fábrica, era importante, pois permitia demonstrar o poder do estabelecimento e tornava mais fácil o acesso do cliente. Já os argentinos fri- 
savam a importância do patrão estar próximo das atividades cotidianas da fábrica, facilitando, assim, os mecanismos de controle e reduzindo os custos de instalação do empreendimento.

As leituras diferentes, e mesmo opostas do espaço (espaço-status e espaço-custo-controle), que em princípio pareciam um problema de fácil resolução, revelaram-se fonte de conflitos, aumentando a desconfiança e criando obstáculo à alavancagem dos negócios.

Evidentemente, não se pode afirmar que as diferentes interpretações do espaço foram a causa de todas as dificuldades para o tão esperado sucesso. Contudo, boa parte do tempo de todos os encontros dos dois grupos, de 1987 a 1992, era ocupada pela discussão do espaço, sem que eles jamais chegassem a uma solução, o que alargava ainda mais a desconfiança. Os problemas da firma eram sempre atribuídos, pelos próprios parceiros, ao erro de alguém, nunca à ausência de acordo sobre a interpretação simbólica do espaço. Foi necessário um inesperado constrangimento exterior para que a clivagem interpretativa fosse ultrapassada, mas por uma imposição do cenário econômico, e não por uma negociação da realidade. Essa ameaça foi o confisco financeiro do governo Collor, que demandou rápida tomada de decisão. Somente nesse momento os brasileiros abriram mão de sua exigência e concordaram com a reunião de todas as atividades empresariais em Alphaville, como desejavam os argentinos.

Como podemos analisar o caso acima descrito e formular algumas conclusões a partir dele? Conviria a abordagem funcionalista, dominante no campo de estudos sobre cultura organizacional, para a compreensão dos conflitos culturais vividos na firma? Será que a concepção da cultura, como um dado objetivo e reificado, algo que a organização possui, é suficiente para fazer avançar o debate sobre cultura organizacional? Essa abordagem não encobre, mais do que esclarece, importantes dimensões do fenômeno?

Além de um problema de disfunção organizacional, os dados etnográficos descritos revelam a produção, pelos sujeitos sociais, de diferentes leituras da realidade. Sendo assim, a abordagem interpretativa mostra-se mais apropriada a uma análise consistente desse caso. Esboçá-la é o intuito das próximas seções deste artigo. Para tanto, inicialmente empreende-se breve revisão de literatura sobre a antropologia simbólico-interpretativa, com o propósito de apresentar o "estado-da-arte" dessa corrente da teoria antropológica. Em seguida, busca-se traduzir essas idéias para o campo dos estudos organizacionais.

\section{METÁFORAS E PRODUÇÃO CIENTÍFICA NAS CIÊNCIAS SOCIAIS}

Geertz (1983a) parte do pressuposto de que a teoria científica move-se principalmente por analogias, por um pensamento metafórico, explicações do tipo como se, ligando o menos inteligível ao mais inteligível. Assim, o coração é visto como se fosse uma bomba, o cérebro como se fosse um computador, a luz como se fosse uma onda e o espaço como se fosse um globo.

O antropólogo norte-americano sugere que, a partir dos anos 1960, ocorreu um giro interpretativo nas Ciências Sociais. Desde então, elas deixaram de ser vistas como uma espécie de ciência natural atrofiada, para serem percebidas como uma ciência diferente. Houve, assim, progressivo abandono das Ciências Naturais como modelo a ser seguido.

Segundo Geertz, as Ciências Sociais distanciaram-se do ideal de explicação voltada para a construção de leis gerais de funcionamento da sociedade, ou para a construção de funções a partir do isolamento de variáveis, que marcara a abordagem positivista. Na nova perspectiva, caberia às Ciências Sociais a construção de interpretações, sempre provisórias, sobre a realidade social, em uma perspectiva compreensiva.

Esse giro interpretativo viria acompanhado do recurso a novas metáforas, para a compreensão do mundo social. Isso porque a mudança de objetivos implica em alteração na retórica analítica, ou seja, quando o curso da teoria muda, as convenções, com as quais se expressa, também mudam. Novas estratégias discursivas, novas narrativas são criadas para apresentar a análise. Sendo assim, cada vez menos representa-se a sociedade como se fosse uma máquina ou um organismo. Ao invés de as metáforas inspiradoras advirem da Física ou da Biologia, elas são procuradas nas humanidades. O jogo, o drama e o texto tornam-se então imagens recorrentes para interpretar a realidade social.

O sociólogo português Boaventura de Sousa Santos parece levar ao extremo a proposição de Geertz. Segundo ele, obstáculos tradicionalmente apontados como barreiras ao desenvolvimento das Ciências Sociais - relacionados basicamente à subjetividade que marca a produção do conhecimento, à interferência do sujeito sobre o objeto, às previsões pouco confiáveis e à impossibilidade da formulação de leis gerais - eclodem hoje também nas Ciências Naturais. Isso acarretou uma ampla revisão da epistemologia da ciência moderna (Santos, 1988). 
Para Boaventura, em função da crise do paradigma dominante, já não presenciamos a predominância do fluxo de metáforas das Ciências Naturais para as Ciências Sociais. O fluxo lhe parece ter-se invertido: as Ciências Naturais é que recorrem às Ciências Sociais como reservatório de analogias. Como exemplos, cita a teoria das estruturas dissipativas do prêmio-nobel Ilya Prigogine e a teoria sinergética de Haken, as quais explicam o comportamento das partículas por meio de conceitos como revolução social, violência, escravatura, dominação e democracia, todos eles vindos das Ciências Sociais.

Todavia, deve-se relativizar o argumento de Boaventura. Hannerz (1997 e 1998) argumenta que a teoria social contemporânea lança mão de metáforas biológicas para pensar novos fenômenos. Hibridação e mestiçagem têm sido recursos metafóricos incorporados pela Antropologia para analisar a produção de significados no contexto da globalização da cultura.

Em um contexto sociohistórico, no qual as fronteiras entre as disciplinas científicas estão sendo revistas, renegociadas e redemarcadas, ou, como diz Geertz (1983a), no qual o traçado do mapa intelectual está sendo redesenhado, ocorre, em verdade, um descentramento dos fluxos conceituais. Fluxos em distintos sentidos, e mesmo refluxos, passam a ser cada vez mais constantes, ainda que os empréstimos conceituais interdisciplinares nem sempre sejam feitos com o devido rigor. A produção científica em Administração, que muitas vezes importa conceitos de outras disciplinas, ignorando entretanto as disputas paradigmáticas que envolvem esses conceitos nas ciências de origem, atesta isso, obrigando-nos a uma certa vigilância.

De toda forma, é correto afirmar que o pensamento metafórico tem marcado a produção científica nas Ciências Sociais. No campo da Administração, Morgan (1988) foi o pioneiro na sistematização da teoria das organizações, a partir da utilização de analogias. Ele apresenta diferentes metáforas que se prestam à compreensão das organizações. Cada metáfora revelaria uma face do fenômeno organizacional. Assim, as organizações podem ser vistas como se fossem máquinas, organismos, cérebros, culturas, sistemas políticos, prisões psíquicas, fluxos ou instrumentos de dominação. Por um lado, a força de sua abordagem reside na perspectiva multidisciplinar. Para analisar a realidade organizacional, Morgan utiliza distintos olhares disciplinares, da engenharia à ecologia, da Antropologia à Ciência Política, das ciências cognitivas à psicossociologia. Por outro lado, no entanto, sua força é também sua fraqueza, pois termina não aprofundando nenhum dos aportes disciplinares.

Na próxima seção, tenta-se pensar como a metáfora da cultura, enquanto um texto ou conjunto de textos, proveniente da antropologia interpretativa, pode ajudar a compreender a dinâmica cultural nas organizações.

\section{CULTURA E PRODUÇÃO SIMBÓLICA: A CULTURA COMO TEXTO}

Clifford Geertz é o mais expressivo representante da antropologia interpretativa ou hermenêutica. Segundo Fischer (1985), esse rótulo expressa uma tendência substantiva que se cristalizou na Universidade de Chicago, nos anos 1960, a partir da liderança de Geertz e David Schneider. Tal corrente da teoria antropológica terminou interessando a quase todo o corpo docente dessa universidade, que incluía expoentes como Victor Turner, Marshall Sahlins e Terence Turner (Fischer, 1985). A partir de então, Geertz tornou-se, junto a Lévi-Strauss, um dos mais conhecidos antropólogos da segunda metade do século XX, tanto no interior quanto no exterior da disciplina antropológica.

Conforme anteriormente afirmado, Geertz (1983a) sugere que as metáforas do jogo, do drama e do texto têm sido privilegiadas pela teoria social contemporânea para que se interprete a realidade social. Ele associa as imagens do jogo e as do drama sobretudo aos trabalhos de Erving Goffman e Victor Turner, respectivamente. No que se refere à utilização da metáfora do texto, cita sua própria produção intelectual. Todavia, ressalta que o recurso a essas metáforas não se dá de forma excludente, pois elas misturam-se na interpretação de um mesmo autor. Sua abordagem parte do pressuposto de que as instituições sociais, os costumes, as mudanças e os atos do cotidiano são passíveis de leitura em algum sentido. Vejamos mais de perto seu pensamento.

Geertz (1973a) pretende recolocar as bases do conceito de cultura na Antropologia, ao passo que apresenta o programa da antropologia interpretativa. Para ele, a definição clássica de cultura proposta por Tylor parece ter chegado ao ponto em que confunde muito mais do que esclarece, levando a produção antropológica sobre cultura a uma espécie de "pantanal conceitual". Trata-se da célebre definição: esse todo complexo que inclui conhecimentos, crenças, arte, moral, leis, costumes, ou qualquer outra capacidade ou 
hábitos adquiridos pelo homem como membro de uma sociedade.

Geertz defende um conceito semiótico de cultura. Baseado na sociologia clássica de Max Weber, para quem o homem só é capaz de viver em um mundo que para si seja dotado de sentido, Geertz entende a cultura como sendo a produção desse sentido, ou seja, uma inextricável teia de significados que os homens tecem em suas interações cotidianas e que funciona como um mapa para a ação social. Seguindo o raciocínio metafórico, Geertz enxerga a cultura como um texto, ou um conjunto de textos, que os atores sociais lêem para interpretar o curso dos acontecimentos sociais.

Se a cultura é um texto, o papel do antropólogo é interpretar esse texto, penetrar em suas emaranhadas estruturas significativas, compreendendo não apenas o que significa, mas como faz sentido, como ganha significado para os sujeitos sociais. A Antropologia passa a ser considerada não mais uma ciência experimental em busca de leis, mas uma ciência interpretativa à procura do significado.

O antropólogo é visto então como um intérprete, um tradutor cultural. Ele interpreta o fluxo do discurso social: falas, silêncios, gestos, ações. Como intérprete, cabelhe traduzir os significados culturalmente construídos pelos sujeitos sociais. Mas vale lembrar que, para Geertz, o antropólogo constrói interpretações de segunda mão, ele interpreta interpretações, lê o texto cultural por sobre o ombro dos nativos. A rigor, são os próprios sujeitos sociais que interpretam em primeira mão sua própria cultura.

Mas, como procede o antropólogo para interpretar uma cultura? A resposta pode ser encontrada no programa da antropologia hermenêutica formulado por Geertz. Se a cultura é uma coleção de textos que os indivíduos escrevem, reescrevem e lêem em suas interações cotidianas, o antropólogo deve tomar parte nessas interações para interpretar esses textos, o que não significa virar um nativo, mas aprender a viver com - e não como - eles, sendo de outro lugar e tendo um mundo próprio, diferente (Geertz, 1983b e 2001). Segue daí a centralidade do trabalho de campo etnográfico na Antropologia professada e praticada por Geertz. E fazer Etnografia, diz-nos ele, é como tentar ler um manuscrito desbotado, cheio de rasuras e emendas. O trabalho etnográfico consiste em ler nas entrelinhas, construir interpretações, sempre provisórias, sempre passíveis de serem questionadas e/ou reconstruídas.

Quiçá seja esta uma boa síntese do programa da an- tropologia hermenêutica proposto por Geertz: a cultura como um texto que os atores sociais lêem para interpretar suas vidas; a Antropologia como uma ciência interpretativa à procura dos significados escondidos por detrás das práticas sociais; e o antropólogo como um intérprete que recorre ao trabalho de campo etnográfico para empreender a tradução dos textos culturais. Esse programa foi elaborado ao longo de suas experiências de campo em Bali, Java e Marrocos. Vejamos mais detidamente um de seus textos etnográficos sobre Bali (Geertz, 1973b).

Vale lembrar que para Geertz (1973a) a boa interpretação é uma descrição densa, isto é, uma descrição microscópica de eventos bem particulares, mas que são capazes de falar algo sobre grandes questões, sobre as sociedades nas quais estão contextualizados. É justamente isso que ele tenta fazer em sua análise da briga de galos em Bali. A escolha da briga de galos como locus empírico privilegiado para a compreensão da sociedade balinesa não é aleatória. Geertz sugere a importância que tal ritual possui na estruturação dessa sociedade. Segundo ele, da mesma forma que os Estados Unidos revelam-se em um campo de beisebol, em um campo de golfe ou em torno de uma mesa de pôquer, Bali revela-se em uma rinha de galos.

Uma frase do texto parece sintetizar o esforço interpretativo de Geertz: "é apenas na aparência que os galos brigam ali - na verdade, são os homens que se defrontam" (Geertz, 1973b). Tal afirmação sustenta-se na observação do comportamento dos sujeitos presentes nas rinhas de galos, no momento em que procedem às apostas. Geertz mostra que existem regras que as presidem, e mais: elas refletem e atualizam a organização social balinesa. Vejamos algumas dessas regras: a) um homem quase nunca aposta contra um galo de seu próprio grupo familiar. Na verdade, sentir-se-á obrigado a apostar nele, especialmente em se tratando de um parentesco mais próximo; b) se seu grupo de parentesco não está envolvido, deverá apostar em um grupo aliado contra um não-aliado, e assim por diante nas redes de aliança, até aquela que envolve toda a aldeia contra uma aldeia vizinha; c) duas pessoas envolvidas em uma situação de hostilidade institucionalizada apostarão ferozmente uma contra o galo da outra, como forma de dramatizar um ataque franco a seu rival; d) inversamente, o término de um conflito e o reatamento de uma relação social pode ser sinalizado mediante a aposta no galo do inimigo; e) em situações desagradáveis, de lealdade cruzada, em que um homem vê-se diante de duas pessoas com as quais possui vínculos 


\section{PEDRO JAIME JÚNIOR}

mais ou menos equilibrados, a melhor opção é sair, evitando a aposta.

A apresentação dessas regras revela a habilidade de Geertz para interpretar o significado daquela prática para os balineses, indo além do sentido econômico que talvez fosse a significação percebida por um observador desavisado - um turista, por exemplo. Para Geertz, a briga de galos é uma dramatização da vida em Bali, uma história que os balineses contam sobre si e para si mesmos. Trata-se de uma leitura balinesa da experiência balinesa.

Tentou-se até aqui apresentar um panorama geral da antropologia hermenêutica, tal como foi formulada por Clifford Geertz. A redefinição do conceito de cultura proposta por esse autor e sua contribuição à literatura etnográfica já lhe conferem a condição de clássico da teoria antropológica. Conseqüentemente, ele atraiu diversos interlocutores, uns mais críticos, outros menos.

\section{ANTROPOLOGIA HERMENÊUTICA: PERSPECTIVAS CRIITICAS}

Entre os interlocutores de Clifford Geertz aqui destacados, alguns estudaram com ele ou realizaram sua formação justamente entre os anos 1970 e 1980, quando a antropologia interpretativa estava se construindo. São antropólogos como George Marcus, Michael Fischer, Paul Rabinow e Vicent Crapanzano. Eles fazem parte da "geração de alunos de Geertz", para usar uma expressão de Fischer (1985). Além desses, outros cientistas sociais, como o antropólogo sueco Ulf Hannerz, o historiador da Antropologia James Clifford e o sociólogo britânico John Thompson, também têm dialogado com a obra de Geertz.

Destacam-se, a seguir, sobretudo as críticas formuladas por Thompson (1995). Podem ser consideradas críticas internas, uma vez que o sociólogo britânico parece concordar com as bases da antropologia hermenêutica, fazendo, no entanto, algumas ressalvas, propondo uma revisão: "A concepção estrutural da cultura é tanto uma alternativa à concepção simbólica, como uma modificação dela" (Thompson, 1995 , p. 182). É a partir dessa revisão que ele formula sua concepção estrutural da cultura, que não deve ser confundida com a perspectiva estruturalista de Lévi-Strauss. Thompson ressalta que os métodos estruturalistas concentram-se nos traços internos das formas simbólicas, ao passo que a concepção estrutu- ral da cultura enfatiza tanto o caráter simbólico dos fenômenos culturais, como o fato de esses fenômenos estarem inseridos em contextos e processos socialmente estruturados. Vejamos, com mais vagar, a argumentação de Thompson.

Conforme lembra, os seres humanos não apenas produzem e recebem expressões lingüísticas. Eles também conferem sentido, significação a construções não-lingüísticas: ações sociais, obras de arte, objetos materiais de diversos tipos, etc. A cultura deve ser vista então como estruturas significativas, como padrões de significado. A análise cultural seria justamente a elucidação das estruturas de significado incorporadas às formas simbólicas. Até aqui, seu pensamento está em plena concordância com o de Geertz.

Entretanto, para Thompson, os fenômenos culturais estão implicados em relações de poder e conflito. Eles podem, mesmo, ser vistos como expressões das relações de poder. Nesse sentido, prestam-se a múltiplas, e talvez divergentes e conflitantes, interpretações. A concepção de Thompson pode ser resumida da seguinte forma: os atores sociais estão posicionados de forma diferente e desigual na estrutura social, sendo portanto possuidores de distintos capitais econômicos, culturais e simbólicos. Dessa forma, eles constroem diferentes interpretações sobre os fenômenos culturais.

Dito de outra forma, o texto cultural está inserido em um contexto sociohistórico, por meio do qual ele é produzido, transmitido, recebido e interpretado. Tudo se passa como se Thompson levasse às últimas consequêencias a metáfora do texto utilizada por Geertz para a compreensão da cultura. Assim, se a cultura é um texto, então - tal como os textos literários -, presta-se a diferentes e, até mesmo, conflitantes interpretações. Sabe-se, com a teoria literária, que os leitores constroem diferentes leituras de um texto, pois possuem distintos conhecimentos prévios devido a suas biografias particulares. Além disso, um mesmo leitor pode construir interpretações diferentes de um mesmo texto ao lê-lo em distintos momentos de sua vida. Analogamente, os atores sociais sempre lêem o mundo a partir de um lugar - do lugar que ocupam na estrutura social, diria Thompson.

Nesse sentido, o sociólogo britânico afirma que Geertz dá uma atenção insuficiente aos problemas de conflito social e poder. Para ele, a antropologia interpretativa de Geertz concentra-se na produção de significados, esquecendo-se de observar os contextos sociais estruturados dentro dos quais esses significados são construídos. 
Thompson aponta também que Geertz volta-se mais para o significado que os fenômenos culturais têm para os sujeitos sociais, do que para os significados, no plural. De fato, se recobrarmos a interpretação sobre a briga de galos em Bali construída por Geertz, e dado que ele afirma ser este um ritual masculino, interdito para mulheres e crianças, poderíamos questionar, com Thompson (1995), o caráter monocórdico que ele parece atribuir à interpretação dos balineses sobre esse texto cultural. Acaso não fariam outras leituras desse evento mulheres e crianças que ficam sempre na periferia das rinhas? Fica a questão.

Na mesma direção da crítica formulada por Thompson vai a ressalva do antropólogo norte-americano Michael Fischer. Em seu artigo Da antropologia interpretativa à antropologia crítica, afirma: "os indivíduos mantêm diferentes posições na sociedade, diferentes percepções, interesses, papéis, e de suas negociações e conflitos surge um universo social-plural no qual podem coexistir e competir muitos pontos de vista opostos" (Fischer, 1985, p. 57). Fischer questiona a idéia da cultura como algo consensual, formulada por Geertz (1973a), para quem a cultura é pública porque o significado o é, ou seja, a cultura é a rede de significados compartilhados, sobre os quais existe um acordo. Contrapondo-se a essa abordagem, e advogando o que considera uma hermenêutica crítica, Fischer afirma ser "uma tarefa etnográfica básica explorar a margem de opiniões em qualquer assunto e avaliar sua profundidade de apoio como um meio de se avaliar, também, quais são as opiniões dominantes e por quanto tempo" (Fischer, 1985, p. 67).

Recuperando mais uma vez o argumento de Thompson (1995), destacamos que suas críticas não devem passar sem a devida relativização. Textos como A política do significado (Geertz, 1973c) e Centros, reis e carisma: reflexões sobre o simbolismo do poder (Geertz, 1983b), além do livro Negara: the theater state in nineteenth century Bali (Geertz, 1980), parecem desautorizar uma crítica sumária ao antropólogo norte-americano pela ausência de preocupações com questões de conflito e poder em sua obra.

De toda forma, quando Thompson (1995) afirma que Geertz volta-se mais para o significado do que para os significados atribuídos aos fenômenos culturais pelos sujeitos sociais, parece corroborar uma crítica lançada pelos representantes da chamada antropologia pós-moderna aos clássicos da teoria antropológica, inclusive ao próprio Geertz. Eles desconstroem as interpretações totalizantes. Vejamos, por exem- plo, o que diz James Clifford: "Ao representar os nuer, os trobiandeses ou os balineses como sujeitos totais, fontes de uma intenção cheia de significados, o etnógrafo transforma as ambigüidades e diversidades de significado da situação de pesquisa em um retrato integrado" (Clifford, 1998, p. 40-41). Esse aspecto é também destacado por Crapanzano (1991), para quem Geertz submete os balineses à generalização expositiva.

Muitos anos depois de Geertz ter empreendido uma redefinição do conceito de cultura, Ulf Hannerz propõe outra revisão. Hannerz (1998) afirma que, no que se refere ao conceito de cultura, há pelo menos três linhas que os antropólogos têm tentado articular de forma mais ou menos harmônica. A primeira, é que a cultura aprende-se, adquire-se na vida social, é algo como um software de que necessitamos para programar o hardware que nos é dado biologicamente. A segunda, é que a cultura está de alguma maneira integra$\mathrm{da}$, formando um conjunto bem encaixado. A terceira, é que os diferentes padrões de cultura correspondem aos distintos coletivos sociais que em geral pertencem a um território.

Desses três pressupostos relativamente consensuais formulados pela teoria antropológica, ele sugere que apenas o primeiro é sustentável no presente contexto. Ante os fenômenos sociais contemporâneos, os demais parecem-lhe difíceis de manter. A idéia de que a cultura é bastante integrada e pode ser captada como um todo não lhe parece plausível em uma época pós-moderna, quando observamos vidas que incluem um conjunto notável de contradições, ambigüidades, malentendidos e conflitos.

Da mesma forma, parece impossível entender a cultura como um padrão de significados e de formas significativas distintas pertencentes a uma coletividade, por sua vez situada em um território, devido à crescente interconexão espacial. À medida que as pessoas deslocam-se com seus significados, e que estes encontram formas de se deslocarem ainda que as pessoas não se movam, os territórios não podem ser demarcadores de uma cultura. Para Hannerz (1998, p. 24), "se aceitamos que a cultura adquire-se e organiza-se socialmente, supor que se distribui de forma homogênea dentro de uma coletividade converte-se em algo problemático quando vemos as diferentes experiências e biografias de seus membros".

Finalizando esta seção, deve-se ponderar o seguinte: se são justas ou injustas as críticas formuladas por John Thompson a Clifford Geertz, é muito difícil avaliar aqui. 
De toda forma, pode-se reter desse debate a importância de uma perspectiva crítica e política na concepção da cultura como produção simbólica. A cultura deve ser vista como uma rede de significados, tecida dentro de um complexo jogo de interações que envolve os conflitos e as relações de poder. Os atores sociais escrevem e reescrevem cotidianamente o texto cultural que, dialeticamente, funciona como um contexto dentro do qual interpretam, organizam e dão sentido a suas vidas. No entanto, tais interpretações não são sempre idênticas e muitas vezes as clivagens interpretativas configuram uma arena de disputas para estabelecer a retórica discursiva "verdadeira".

Tendo-se feito essa breve reconstrução do debate em torno da antropologia hermenêutica, busca-se, na próxima seção, operar a transposição dessas idéias para pensar a dinâmica cultural nas organizações.

\section{CULTURA E GESTÃO DE ORGANIZAÇÕES: UMA ABORDAGEM HERMENÊUTICA}

Assumir uma abordagem hermenêutica é entender que a cultura organizacional, tal como um texto, não é apenas passível de leitura, como também presta-se a uma multiplicidade de interpretações. Além disso, nas interpretações que fazem sobre ela, os indivíduos estão constantemente relacionando esse texto a outros, cultural, social ou historicamente associados. Dito de outra forma, a organização produtiva é um espaço de socialização inserido em uma rede de socialização mais ampla. Decorre daí que a organização não pode ser vista como uma microssociedade ou um sistema fechado, como o fazem muitos teóricos e/ou consultores de cultura organizacional.

Não podemos esquecer que os sujeitos sociais que compõem a organização, gestores e trabalhadores, antes de serem membros de uma organização produtiva, ou melhor, concomitantemente a esse status, são portadores de filiações políticas, crenças religiosas, possuem seus grupos de referência, suas parentelas, suas origens étnicas e regionais, suas preferências sexuais, suas formações profissionais, suas histórias de vida, enfim, múltiplas localizações identitárias. Como bem lembra Sainsaulieu (1987), os atores sociais não deixam de lado suas identidades e culturas ao passarem pela portaria da organização. Cabe ao analista desvendar quais dessas localizações sociais funcionam como códigos estruturantes da dinâmica cultural na organização em análise. A importância que tomam as rela- ções raciais em uma sociedade pode ser equivalente ao papel que jogam as relações inter-étnicas ou as relações de gênero em outro contexto.

Como se isso não bastasse, tais atores estão posicionados de forma diferente e desigual na estrutura social e inserem-se, nesses mesmos termos, na estrutura organizacional, o que sinaliza para uma outra localização social: o pertencimento de classe. Toda essa complexidade possui influência marcante na diversidade de interpretações a que se presta a cultura organizacional, entendida como um texto.

Utilizar a metáfora do texto é chamar a atenção para o fato de que, se a cultura organizacional, que seria o texto, oferece múltiplas possibilidades de interpretação a seus leitores - acionistas, gestores, trabalhadores, clientes, fornecedores, governantes, sindicalistas e outros representantes da sociedade civil organizada-, seria uma certa miopia acreditar que se vai conseguir levar todos os que compõem a organização a adotar uma visão comum ou consensual do que seja essa cultura - malgrado todos os esforços dos dirigentes, que podemos caracterizar como operações ideológicas, no sentido marxista, ou seja, como tentativas de naturalizar a construção social da realidade, escamoteando as relações de poder. Seria exigir que todos lessem o texto da mesma forma, ou seja, que negassem suas trajetórias particulares, seus panos de fundo culturais, para efetuar uma interpretação orientada para a mesma direção. As críticas à antropologia interpretativa apresentadas na seção anterior deste artigo desautorizam essa crença ingênua.

Por um lado, devemos ter claro que a alta gerência possui um importante papel de poder - é bom que se frise - no jogo de interações que conforma a cultura organizacional. Mas, por outro lado, os discursos e as ações simbólicas desses gestores não possuem um sentido monocórdico quando nos colocamos no âmbito de sua recepção. Em outras palavras, as representações que os dirigentes constroem sobre a organização são reelaboradas, ressignificadas, ressimbolizadas pelos diversos atores sociais. Sendo assim, não existem "verdadeiras" culturas organizacionais, tampouco culturas fortes ou fracas, mas distintas versões sobre a cultura organizacional, isso porque, como bem afirma Vallé (1985, p. 242), "não há percepções 'oficiais' do mundo".

Não se trata de negar toda e qualquer possibilidade dos indivíduos nas organizações chegarem a construir uma comunidade interpretativa, isto é, uma comunidade fundada em esquemas interpretativos comuns, em 
significados compartilhados. De fato, essa possibilidade existe. Mas o espírito crítico deve levar o analista a suspeitar de toda análise sobre a cultura organizacional que contorne, de forma desavisada, a questão do conflito e das relações de poder, pois muito possivelmente essas questões levam a clivagens, a diferenças de interpretação sobre a cultura organizacional. Somente o complexo jogo de interações, no qual estão inseridos os atores sociais, pode nos mostrar como a realidade organizacional é permanentemente negociada.

Finalizando esta seção, gostaria de destacar que, de uma perspectiva hermenêutica, a cultura organizacional deve ser vista, simultaneamente, como um texto polissêmico - que os indivíduos escrevem e reescrevem por intermédio de suas interações cotidianas dentro e fora do espaço organizacional - e um contexto dentro do qual interpretam e dão sentido às suas experiências no universo do trabalho. Ela não pode ser entendida senão como um palco de disputas, um complexo jogo político entre atores sociais portadores de diferentes capitais econômicos, culturais e simbólicos, recursos que são distribuídos de forma desigual na estrutura da sociedade, configurando, assim, distinções, desigualdades sociais. Desigualdades estas que, dialeticamente, refletem-se e atualizam-se nas organizações.

\section{CONSIDERAÇÕES FINAIS}

A polêmica questão da cultura organizacional constitui grande debate no âmbito dos estudos organizacionais desde o final dos anos 1970. Diversos autores que abordam o tema, sobretudo aqueles que se filiam à linhagem funcionalista desse campo do saber, parecem desconhecer os desenvolvimentos mais recentes da disciplina antropológica no tratamento do conceito de cultura. Talvez por essa razão, eles sustentam o pressuposto ingênuo - ou ideológico? - de que a cultura pode ser gerenciada, o que causou certo desconforto a alguns representantes do paradigma crítico. Em virtude do incômodo que sentiram com o aprisionamento do cultural sob a égide da racionalidade instrumental, alguns destes últimos parecem negar a existência da cultura organizacional.

O pano de fundo deste artigo é a crítica à visão gerencialista da cultura. Todavia, acredita-se que a postura de oposição em relação a todo e qualquer reducionismo não deve nos impedir de ver a realidade organizacional como uma construção cultural e simbóli- ca. O caso da firma, aqui apresentado, demonstra que as clivagens interpretativas sobre a realidade organizacional, construídas em diferentes situações do cotidiano administrativo, podem resultar em conflitos culturais com conseqüências concretas para a gestão. Portanto, ao invés de negar esse tema, é preciso fazer avançar o debate. Nesse sentido, encerra-se este artigo com algumas observações de caráter teórico:

a) O ser humano é um animal simbólico. Ele organiza suas experiências e ações por meios simbólicos, isto é, por intermédio de valores e significados que não podem ser determinados por propriedades biológicas ou físicas. De fato, como bem sinaliza Marshall Sahlins, nenhum outro animal estabelece a diferença entre água potável e água benta, pois não há diferença, quimicamente falando. Assim, a ordenação do mundo em termos simbólicos é uma capacidade singular da espécie humana (Sahlins, 1997).

b) Os recentes avanços do debate antropológico sobre cultura sugerem que não é mais possível pensá-la como um universo autônomo e internamente coerente, exceto, talvez, como uma distorção reveladora (Rosaldo, 1989). A cultura deve ser vista como um recurso dentro de uma luta política ligada ao jogo das interações e às circunstâncias. Como bem destaca Clifford (1998), assim como uma língua é a interação e a luta de dialetos regionais, de jargões profissionais, da fala de diferentes grupos etários, etc., uma cultura é, concretamente, um diálogo em aberto, criativo, de subculturas, de membros e não-membros, de diversas facções.

c) É possível traduzir o debate da teoria antropológica contemporânea em torno do conceito de cultura para o campo dos estudos organizacionais. Essa tradução deixa claro que a busca incessante da corrente funcionalista por uma cultura organizacional forte (sic!), isto é, um sistema simbólico harmônico que leve à maximização da performance organizacional, é, em verdade, uma distorção que revela uma operação ideológica: a pretensão de mascarar a construção da realidade organizacional.

d) É preciso analisar a dinâmica cultural nas organizações a partir de uma nova abordagem conceitual, que esclareça, mais do que encubra, importantes dimensões desse fenômeno.

Espera-se que a contribuição prestada neste texto possa fazer avançar as discussões sobre cultura organizacional, superando os limites deixados pela vertente funcionalista. Foi com esse propósito que se buscou traduzir as idéias originárias da antropologia interpretativa para pensar esse tema. Todavia, tal esforço está 


\section{PEDRO JAIME JÚNIOR}

apenas no início. A obra de Clifford Geertz é muito vasta, bem como a de seus interlocutores. Aqui somente esboçou-se um diálogo entre eles, tanto por falta de espaço, quanto por sua riqueza e dinâmica. De toda forma, acredita-se firmemente ser a perspectiva hermenêutica uma via de enriquecimento para a teoria das organizações.

\section{Artigo recebido em 17/07/2001. Aprovado em 04/06/2002.}

\section{Referências bibliográficas}

AKTOUF, Omar. Le symbolisme et la 'culture d'entreprise': des abus conceptuels aux leçons du terrain. In: CHANLAT, J.-F. (Dir.). L'individu dans l'organisation: les dimensions oubliées. Québec : Presses de L'Université Laval, 1990.

CLIFFORD, James. Sobre a autoridade etnográfica. In: CLIFFORD, James. A experiência etnográfica: antropologia e literatura no século XX. Rio de Janeiro : Ed. UFRJ, 1998.

CHANLAT, J.-F. Vers une anthropologie de l'organisation. In: CHANLAT, J.-F. (Dir.). Lindividu dans l'organisation: les dimensions oubliées. Québec: Presses de L'Université Laval, 1990.

CRAPANZANO, Vicent. El dilema de Hermes: la máscara de la subversión en las descripciones etnográficas. In: CLIFFORD, James, MARCUS, George (Eds.). Retóricas de la antropología. Madrid : Júcar, 1991.

DUPUIS, Jean-Pierre. Anthropologie, culture et organisation: vers un modèle constructiviste. In: CHANLAT, J.-F. (Dir.). L'individu dans l'organisation: les dimensions oubliées. Québec: Presses de L'Université Laval, 1990.

FISCHER, Michael. Da antropologia interpretativa à antropologia crítica. In: Anuário Antropológico/83. Rio de Janeiro : Tempo Brasileiro, 1985.

GEERTZ, Clifford. Thick description: toward an interpretive theory of culture. In: The interpretation of cultures. New York : Basic Books, 1973a.

GEERTZ, Clifford. Deep play: notes on the Balinese cockfight. In: The interpretation of cultures. New York : Basic Books, 1973b.

GEERTZ, Clifford. The politics of meaning. In: of cultures. New York: Basic Books, 1973c.

The interpretation

GEERTZ, Clifford. Negara: the theater state in nineteenth century Bali. Princeton : Princeton University Press, 1980.

GEERTZ, Clifford. Blurred genres: the reconfiguration of social thought. In: Local knowledge: further essays in interpretive anthropology. New York: Basic Books, 1983a.
GEERTZ, Clifford. Centers, kings and charisma: reflections on the symbolics of power. In: ______. Local knowledge: further essays in interpretive anthropology. New York : Basic Books, 1983b.

GEERTZ, Clifford. Nova luz sobre a antropologia. Rio de Janeiro : Jorge Zahar, 2001.

HANNERZ, Ulf. Fluxos, fronteiras, híbridos: palavras-chave da antropologia transnacional. In: Mana - Estudos de Antropologia Social, v. 3, n. 1. Rio de Janeiro : PPGAS-Museu Nacional/UFRJ, 1997.

HANNERZ, Ulf. Conexiones transnacionales: cultura, gente, lugares. Madrid : Cátedra, 1998

MORGAN, Gareth. Images of organizations. London : Sage, 1988.

PÉPIN, Normand. Cultura de empresa. Nascimento, alcance e limites de um conceito. In: Mosaico - Revista de Ciências Sociais, v. 1, n. 1. Vitória UFES-CEG, 1998.

ROSALDO, Renato. Culture and truth: the remaking of social analysis. Boston : Beacon Press, 1989.

RUBEN, Guilhermo. O nacional no mercado internacional: empresários e globalização. In: KIRSCHNER, Ana Maria, GOMES, Eduardo (Orgs.). Empresa, empresários e sociedade. Rio de Janeiro : Sette Letras, 1999.

SAHLINS, Marshall. O 'pessimismo sentimental' e a experiência etnográfica: por que a cultura não é um 'objeto' em vias de extinção. In: Mana - Estudos de Antropologia Social, v. 3, n. 1. Rio de Janeiro : PPGASMuseu Nacional/UFRJ, 1997.

SAINSAULIEU, Renaud. Sociologie de l'organisations et de l'entreprise. Paris : Presses de la Fondation Nationale des Sciences Politiques/Dalloz, 1987.

SANTOS, Boaventura de Souza. Um discurso sobre as ciências. Porto Afrontamento, 1988.

SCHWARTZMAN, Helen. Ethnography in organizations. London : Sage, 1993.

SMIRCICH, Linda. Concepts of culture and organizational analysis. Administrative Science Quartely, v. 28, n. 3. Cornell University, 1983.

THOMPSON, John B. Ideologia e cultura moderna. Petrópolis : Vozes, 1995

VALLÉ, Lionel. Représentations collectives et sociétés. In: CHANLAT, Alain, DUFOUR, M. (Dir.). La rupture entre les entreprises et les hommes. Montréal : Québec/Amérique, 1985.

WRIGHT, Susan. Culture in anthropology and organizational studies. In:___ (Ed.). Anthropology of organizations. London : Routledge, 1994 